Document downloaded from:

http://hdl.handle.net/10251/176336

This paper must be cited as:

Cabezos Bernal, PM.; Cisneros Vivó, JJ. (2020). Single-Row Spherical Domes in Stereotomy Treatises. Nexus Network Journal. 22(4):853-869.

https://doi.org/10.1007/s00004-020-00502-3

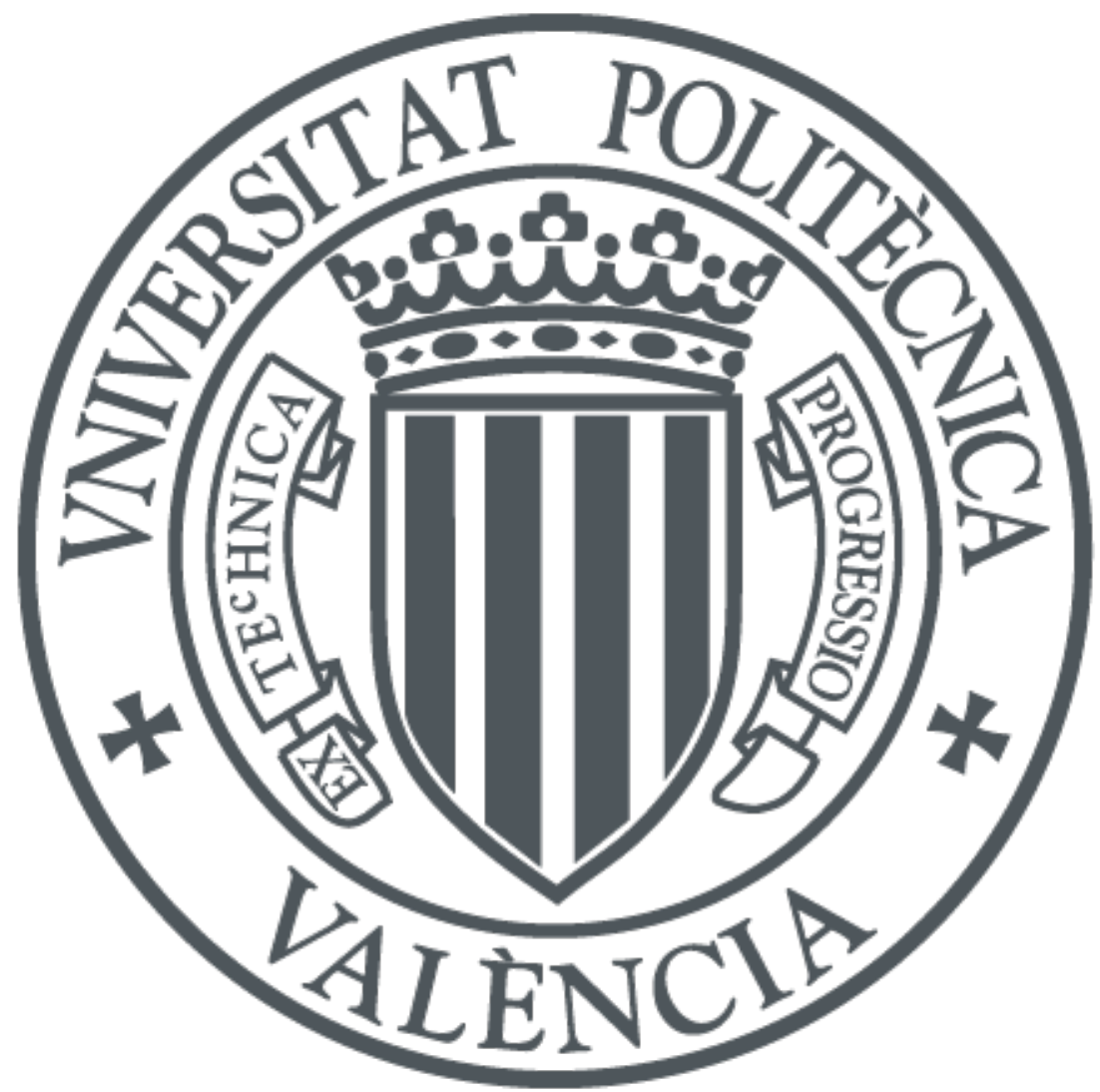

The final publication is available at

https://doi.org/10.1007/s00004-020-00502-3

Copyright Springer-Verlag

Additional Information 


\title{
Single-Row Spherical Domes in Stereotomy Treatises
}

\author{
Cabezos-Bernal, P. M. \& Cisneros-Vivó, J. J. - Nexus Network Journal, 22, pp.1-19
}

\section{Abstract}

This article focuses on analysing and modelling geometrically a complex vault typology, known as single-row spherical dome, which was defined in several classic stereotomy treatises. The peculiarity of this kind of dome is that all their stone pieces are different, since there is a helical directrix defining the upper and lower edges of the pieces. Different solutions will be compared and analysed, both from a graphical and a mathematical point of view, by describing the spatial helixes. The accuracy of the different methods described in the treatises for tracing the stone templates will be also tested. To conclude, some examples of virtual $3 \mathrm{~d}$ modelizations and $3 \mathrm{~d}$ printed models will be exposed.

Keywords: Stereotomy, 3D modelling, vault, helix, spiral, sphere

\section{Introduction}

The art of stone cutting applied to the construction of architectural elements, technically known as stone stereotomy, is a discipline whose practice is virtually extinct today. However, these methods still cause fascination, especially among geometers, mathematicians and lovers of artisanal construction techniques. Even some researches as Fallacara \& Barberio (2018) and Gadaleta (2018), promote a rebirth of a new stereotomy adapted to present skills and techniques.

Mastering traditional stereotomy implies a great knowledge on descriptive geometry, since tracing the shapes of the templates that are used to carry out the carving of the pieces is an example of technical skill. The knowledge of stereotomy was transmitted with suspicion from masters to disciples in the antiquity, but this wisdom was disseminated little by little in the Renaissance as evidenced by the appearance of several manuscripts and stereotomy treatises, which were developed mainly in Spain and France.

One of the first manuscripts on stereotomy was the recently attributed to the architect Pedro de Alviz (Gómez Martínez 1998), whose completion date is estimated around 1544 (García Baño 2017). Only a single copy of this manuscript is preserved in the National Library of Spain [mss. 12686].

The complete manuscript of the Castilian architect Alonso de Vandelvira, carried out around 1585, is also of special relevance. Only two handmade copies of the lost original manuscript are preserved. One of them is in the National Library of Spain [mss. 12719], while the other is in the Library of the Higher School of Architecture of the Polytechnic University of Madrid [mss. R10]. Some facsimile editions of this book were edited by Barbé-Coquelin (1977) and Palacios (2015).

The first published treatise including the practice of stereotomy was carried out by the French architect Philibert De l'Orme, in the third and fourth book of L'Architecture (De L'Orme 1567), which had much influence on successive treatises.

Stereotomy treatises often show surprising solutions, sometimes unnecessarily complex, that are a great technical and artistic challenge. Perhaps this fact comes from one of the main motivations of the human being, the notion of self-development and the immense satisfaction that produces to solve complex problems or to create beautiful things. This personal improvement may imply the recognition of others or even having a place in history. It may be this feeling what encourages human beings to develop works that push them to the limits of their abilities. That results in many astonishing masterpieces that surprise people by their complexity and beauty.

This article focuses on analysing and modelling geometrically one of these constructive boasts. It is a complex spherical dome solution, which is defined in several classic stereotomy treatises. The 
peculiarity of this kind of dome is that all their pieces are different, since there is a helical directrix contained in the hemispherical surface that defines the spatial distribution of the stone pieces.

Rabasa (2013) calls them, very accurately, single-row spherical domes. They supposed a great challenge for masonry masters, so numerous templates had to be drawn to elaborate their stone pieces. Moreover, the tracing process of these templates was geometrically complex as well as carving the pieces due to the complexity of the face surfaces.

\section{Tracing and Carving Process}

For a better understanding of the properness of the methods that will be discussed onwards, it is necessary to explain some considerations about the tracing methodologies of the templates, as well as some details about the carving process of the stone pieces.

The stone pieces of a spherical dome, technically known as voussoirs, are mostly delimited by 6 faces. The voussoir face that is visible from the inside part of the vault is called intrados, while its opposite face is called extrados. Both these faces are theoretically concentric spherical surfaces. Nevertheless, the extrados face is usually not carved in detail, since this face is hidden inside the masonry. The two lateral contact faces between voussoirs are flat and they are contained in vertical planes. The remaining contact faces, the upper and lower one, are technically called bed faces and they transmit most of the vertical loads over the dome by the arch effect. In the conventional case of spherical domes, which are constructed in several horizontal rows, the beds are conical surfaces and there is only one type of pieces per row. However, in the typology in which this article is focused, the bed faces are ruled surfaces with helical directrices (Fig. 1).

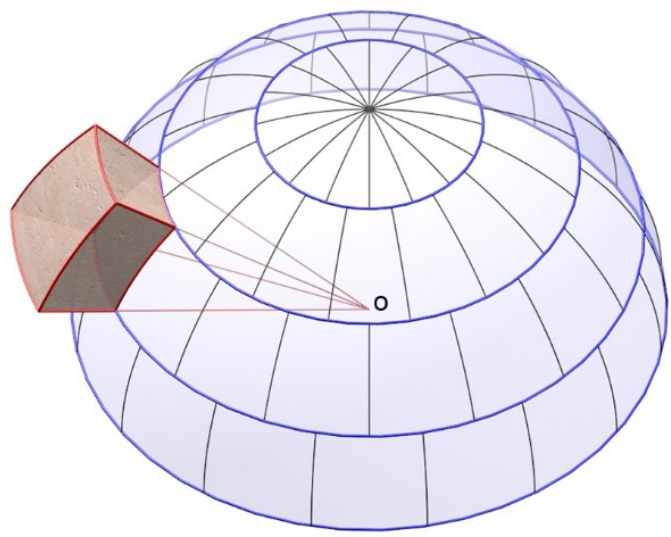

Conventional Multi-Row Spherical Dome

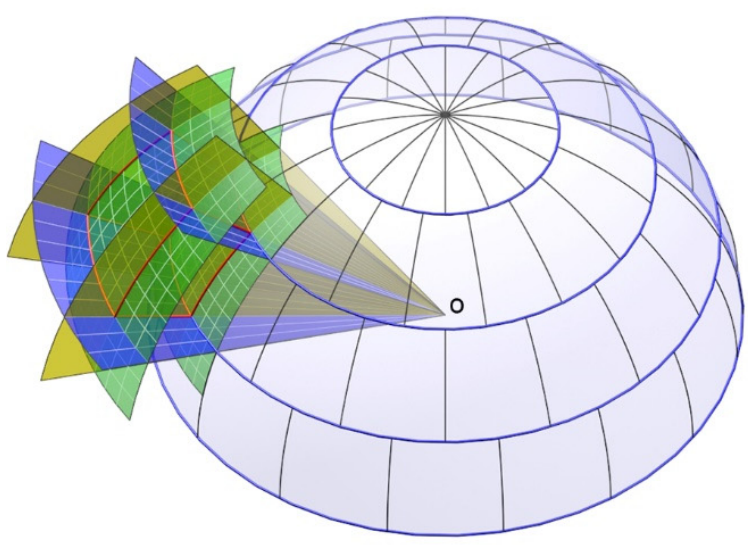

Spherical Surface
Conical Surface

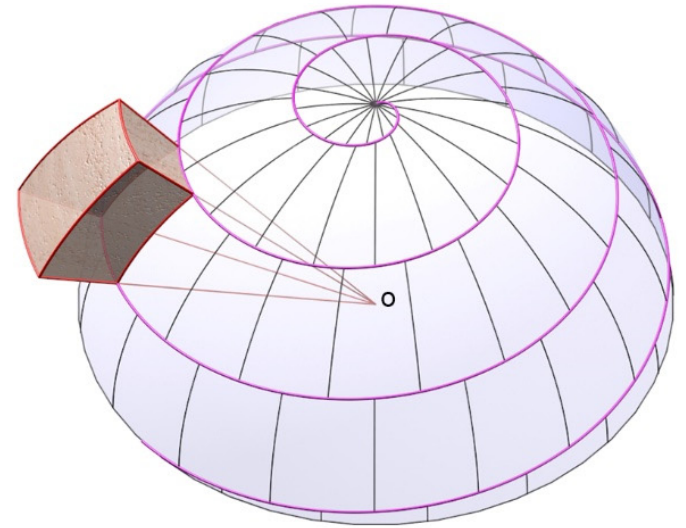

Single-Row Sperical Dome

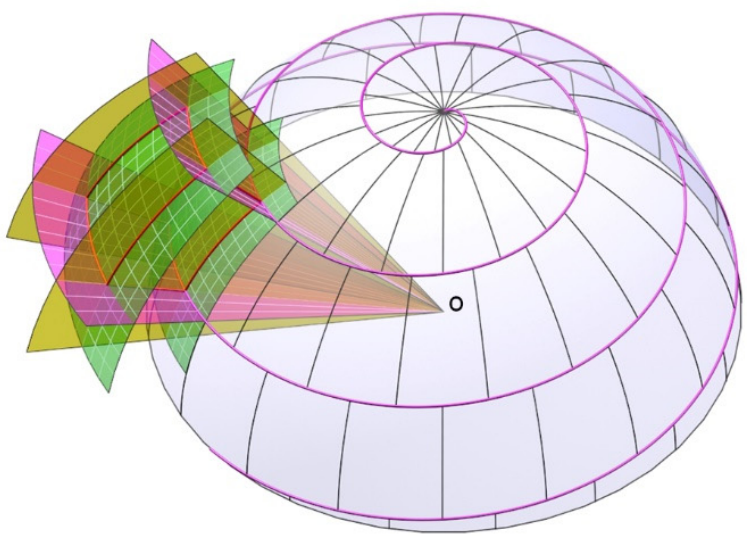

Ruled Surface
Planar Surface

Fig. 1 Voussoir sample in a Multi-Row and in a Single-Row Spherical Dome 
It is important to mention that a spherical surface is a non-developable surface so, in order to obtain the intrados templates of the voussoirs, some simplifications have to be taken into account. In the stereotomy treatises, this problem was reduced to find the nearest developable surface. Therefore, they assimilated cone surfaces to spherical surfaces. For instance, in the case of a conventional multirow spherical dome, the intrados faces of voussoirs are limited by parallels and meridians of the sphere, forming a spherical quadrilateral. The simplification, in this case, consisted in considering the cone portion inscribed inside the spherical quadrilateral (Fig. 2). This cone portion is limited by two of their generatrixes that are the chords of the meridian arcs of the spherical quadrilateral. The portion of the cone is also limited by the parallel arcs of the spherical quadrilateral, which are also contained in the cone surface.
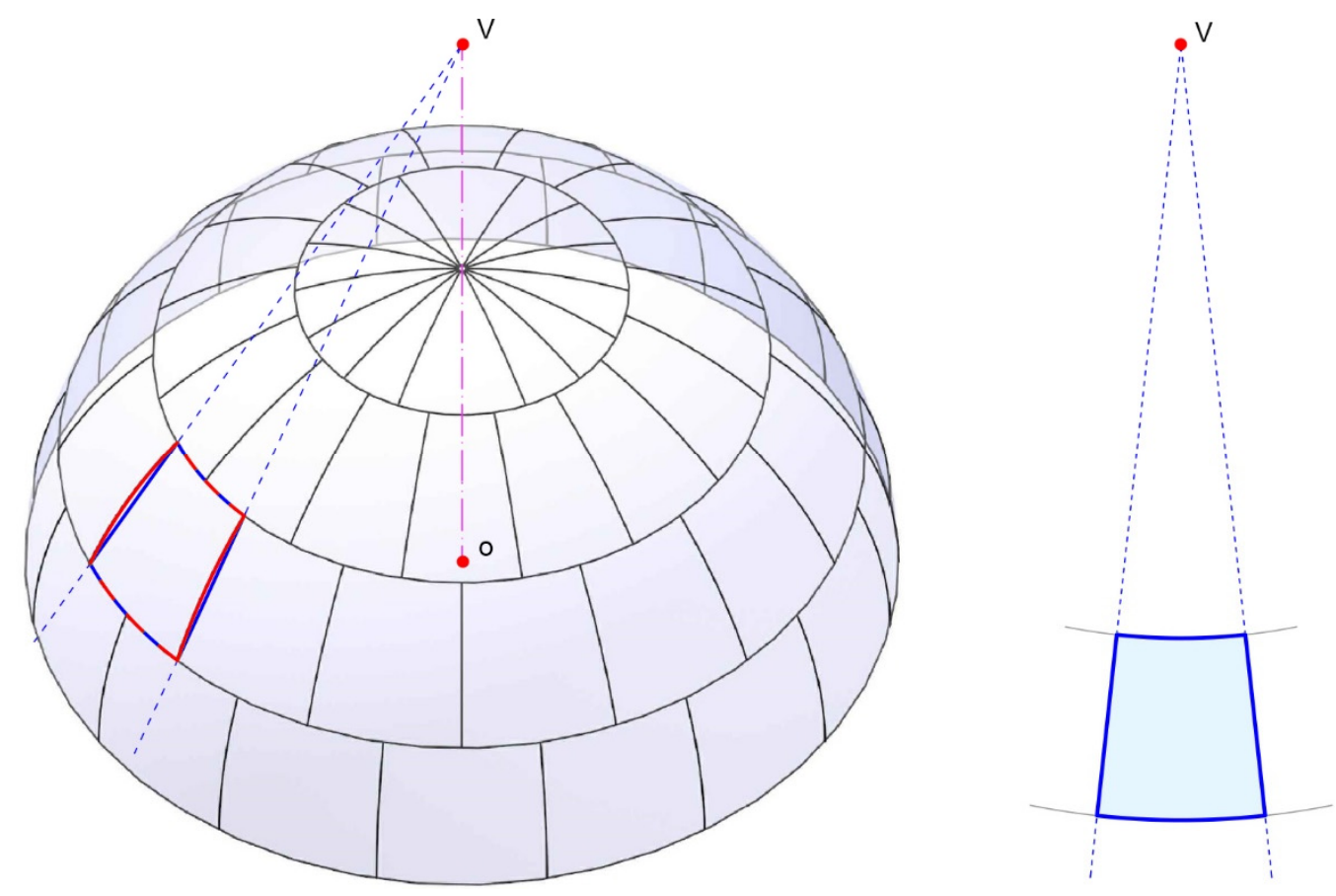

Fig. 2 Cone surface inscribed in a spherical quadrilateral. Development of the cone surface

The developing method consisted in tracing the border generatrixes of the cone with their same spatial angle. Then, they were closed by two concentric circumference arcs centred in the intersection of the traced generatrixes, which is the cone apex. This developing method was approximated, since the length of the arcs resulted a bit underestimated, but it was accurate enough for being used as the intrados templates for the common-sized pieces.

This single intrados template provided enough information to the stonecutters to complete the entire voussoir, since they used two specific tools named Cercha and Baivel, in Spanish. The Cercha was a sort of wooden rule with a curved edge with the same radius as the dome, which was made specifically to give the right concavity to the voussoirs during the carving process. The Baivel was a tool composed by a Cercha joined to a straight rule at right angle in one of their ends. Using this tool, the stonecutter could carve the beds and the lateral faces of the voussoirs (Fig. 3).

The standard workflow to carve a spherical voussoirs is explained in various stereotomy manuscripts and treatises, as explained by Rabasa (2005). Initially, one of the faces of the stone block would be carved with the right concavity with the help of the Cercha. Then, the shape of the intrados template would be transferred to this carved surface. In order to do so properly, the template had to be flexible enough to be placed touching the carved surface only with the curved edges of the template. Laying the entire template on the spherical carved surface would be problematic since, as it is a non- 
developable surface, geometrical distortions would be produced. Nevertheless, they will be admissible as long as the concavity is moderate. Finally, the stonecutter would use the Baivel, laying its inner corner on the intrados edges, as a guide to carve the rest of the faces of the voussoir with the appropriate angles.
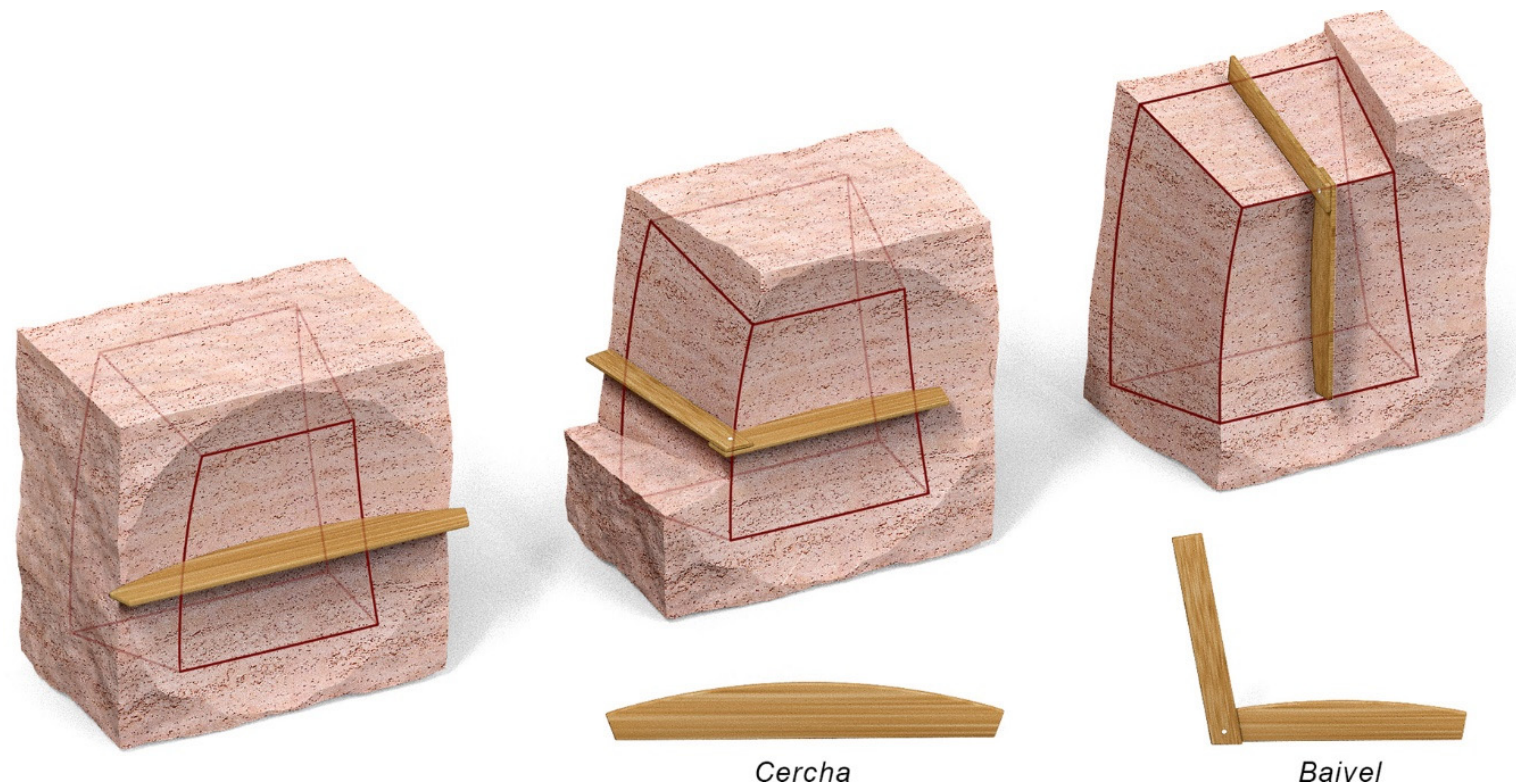

Fig. 3 Carving process of a voussoir from the intrados template using reference tools such as the Cercha and the Baivel

\section{Single-Row Domes}

The single-row spherical typology was initially described in the treatise by De L'Orme (1567) and also in the Vandelvira's manuscript (ca. 1585). Nonetheless, these proposals have noticeable design differences, as shall be discussed later.

De L'Orme refers to this vault as "voute en forme de coquille de limaçon" (snail shell-shaped vault). As the author himself says: "Le traict est fort ingénieux et de gentil sprit" (The tracing is very ingenious and of a gentle spirit) (De L'Orme 1567:119).

Fig. 4 shows the illustration presented by De L'Orme. The geometrical analysis reveals the false spiral or two centres volute that the author traced by dividing the vertical diameter of the vault into 21 equal modules. The central circumference defining the intrados of the keystone has one module of diameter. The centres of the arcs generating the volute are located on the vertical diameter. The radius of the arcs increases every 180 degrees to form a 5 turns volute, which maintains a constant spire step of 2 modules.

This volute was projected orthogonally onto a hemispherical surface, thus providing a curve that is the result of the intersection between some cylinders and the hemispherical surface. As shown in Fig. 5, the spatial configuration of the stones is quite unbalanced, since the voussoirs located at the lower part of the dome are much taller than the rest. De L'Orme tried to dissimulate this problem in the auxiliary section by dividing the first voussoir into two parts. Actually, this would be a very awkward solution in practice, as it is also mentioned by Rabasa (2003). Another aesthetical issue is the insertion of an extra-large voussoir every turn to maintain the brickwork pattern. 

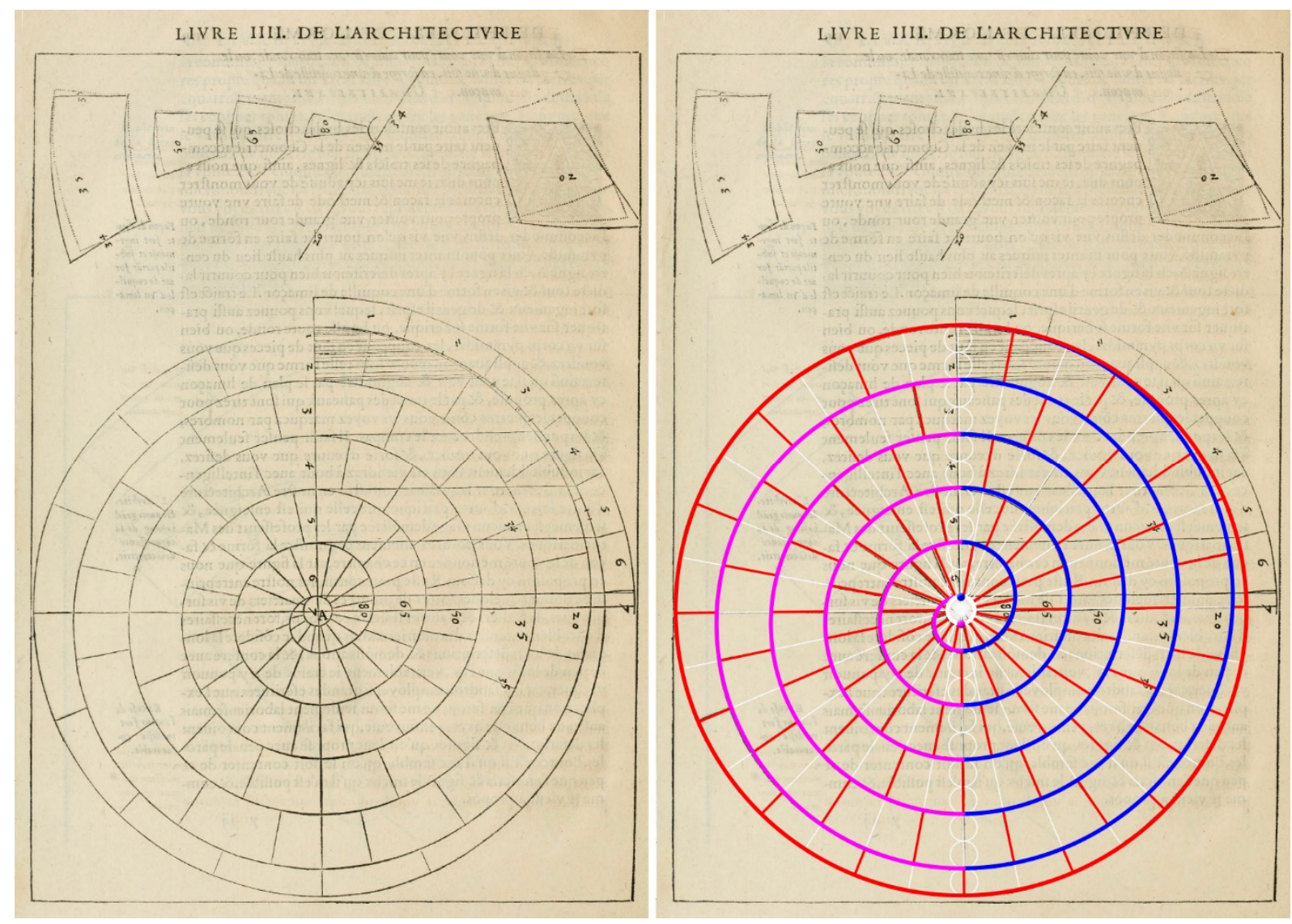

Fig. 4 Illustration in the manuscript by De L'Orme (1567:120). Proportions and geometrical modelization

The author includes a vague textual description, without any indication about the geometric constructions. De L'Orme excuses himself for not providing a detailed explanation that, according to him, would be long and tedious and would bore those awake-minded readers, who will understand the process without any difficulty after seeing the illustration:

"[... ] quand je considère la longueur de leurs descriptions et démonstrations, et la confère avec ce peu de loisir que j'ai, véritablement je crains de n'y pouvoir vaquer, car il y faudrait employer si grandes écritures que l'explication que j'en ferais, ne me serait seulement laborieuse, mais aussi aux bons esprits fort ennuyeuse, qui facilement conçoivent les descriptions et figures qu'on leur propose avec peu de paroles" (De L'Orme 1567:119).

The truth is that the complexity of this vault seems to surpass even the author himself, who fails to correctly solve the intrados templates of the vault. Initially, De L'Orme traces, with dot line, what seems to be an auxiliary intrados shape, obtained as in the case of a conventional multi-row spherical dome voussoir. This auxiliary voussoir would almost fit with the considered voussoir, but they would share only one of their lateral faces. Then he attempts to obtain the intrados shape of the considered voussoir from the auxiliary tracing. However, what would have been a good starting strategy, results incomprehensibly in a template contour that is too far from being somewhat correct. Certainly, the problem that arises is quite complicated, especially at a time when technical drawing procedures were not completely defined.

Analysing the geometric problem from the present point of view is undoubtedly infinitely easier than 450 years ago, since Descriptive Geometry methodology is fully developed and CAD software can be used to solve geometric problems directly in a three-dimensional space. 

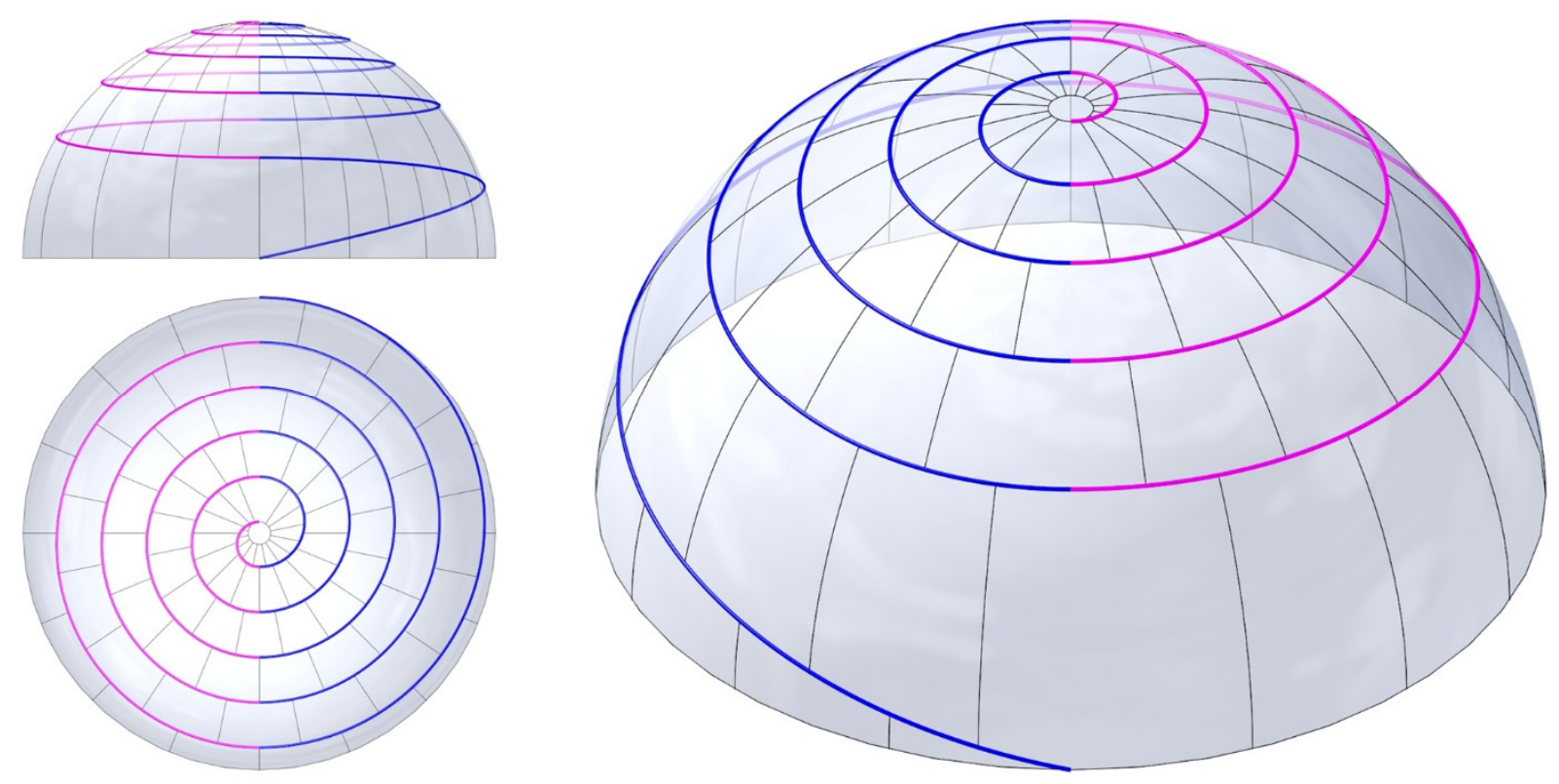

Fig. 5 Intrados face of De L'Orme's dome. The spatial curve generated by projecting the volute on the hemisphere

De L'Orme's treatise had a great influence and some later authors included this typology with minor changes, as will be exposed later. That was not the case of Vandelvira, who presented a radically different design approach that nothing has to do with De L'Orme's proposal. There is no evidence of constructed domes of this kind in France (Rabasa 2003). However, there are some examples in Spain, one of them in the Cathedral of Murcia that was constructed before De L'Orme's Treatise. So, as mentioned by Calvo \& Alonso (2005), this case could be an influence for French authors.

Continuing chronologically with the geometric analysis of this type of domes, is the turn for the case exposed in Vandelvira's manuscript (ca.1585). It is important to mention that this proposal was only exposed in one of the copies of Vandelvira Treatise, specifically, in the copy made by Bartolomé de Sombrigo y Salcedo, preserved at the Library of the Higher School of Architecture of the Polytechnic University of Madrid [mss. R10].

Vandelvira called this case "Capilla redonda en buelta capaço", it could be literally translated as rounded chapel turning as a wicker basket. Vandelvira calls rounded chapel "capilla redonda" to a spherical dome, and he refers to a wicker basket "capazo" (as it is correctly written nowadays in Spanish) because of the helical disposition of the fibres in a basket made out of wicker.

Fig. 6 shows the illustration presented by Vandelvira, which was complemented with a complete textual description explaining the graphical procedures. The author divided the equator of the dome into 16 parts. Consequently, the vertical contact faces between voussoirs are located on the sheaf of planes containing the dome polar axis and passing though these divisions.

In order to trace the helical curve defining the directrix of the voussoirs beds, Vandelvira drew an auxiliary frontal view, in which a quarter of meridian was divided into 56 parts, that is the result of multiplying the 16 divisions in the plan by 3,5 , so as to construct the spiral describing three and a half turns from the equator to the pole, as it can be seen in Fig. 6 . Since this meridian is seen in true shape, the distance between each point of the curve and the polar axis of the dome was measured and transferred to the plan on the radial division, thus obtaining some points of the horizontal projection of the curve, which Vandelvira interpolated manually among them. 


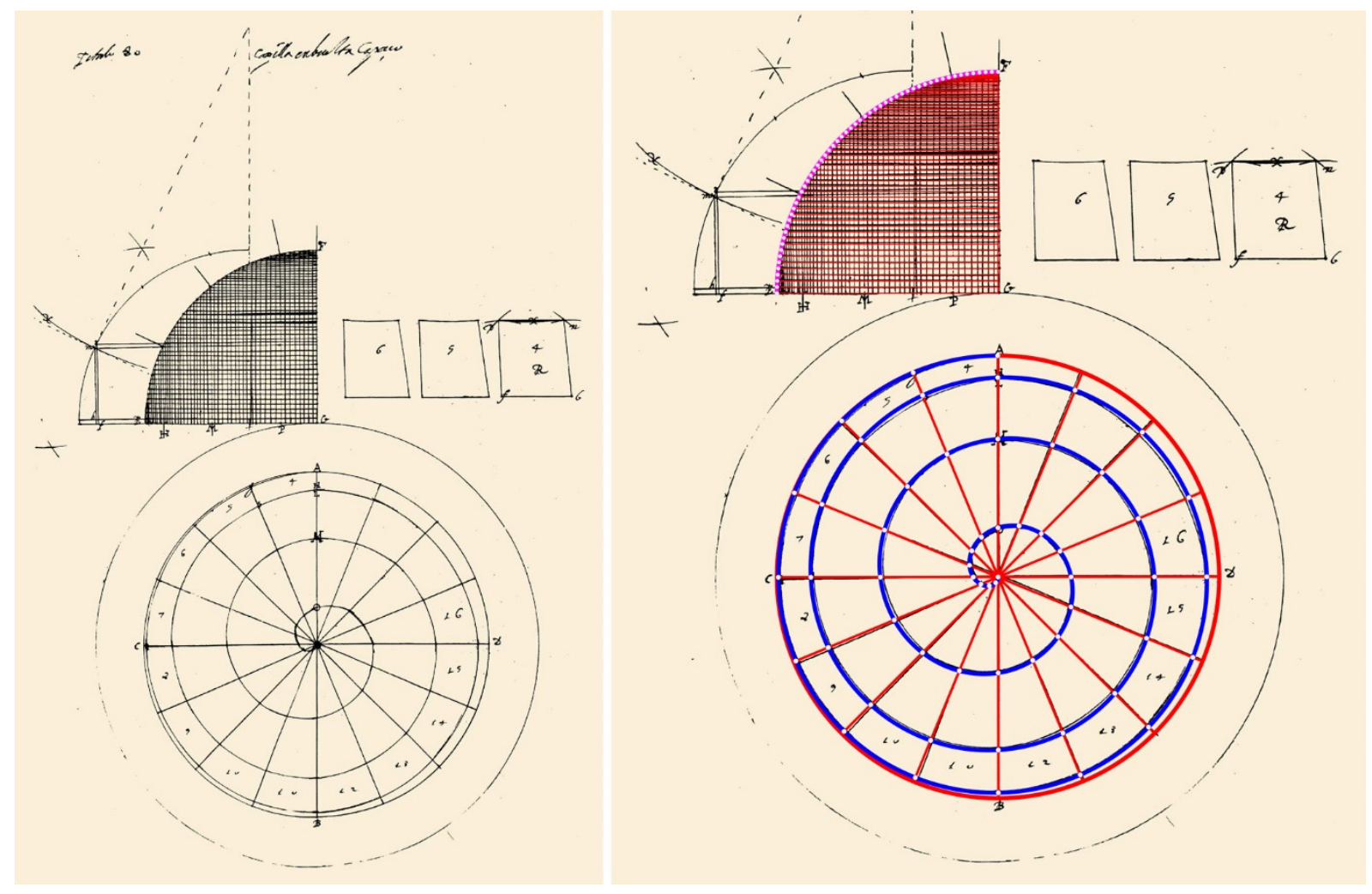

Fig. 6 Illustration in the manuscript by Alonso de Vandelvira (ca. 1585:65). Geometrical construction of the curve.

This results in a mathematically accurate curve, which is known as a Clelia Curve or Spherical Spiral. The Clelia is generated by a point moving at constant speed along a meridian of a sphere while this meridian rotates, also at constant speed, around the polar axis.

Vandelvira defined graphically this curve almost one hundred and fifty years before its mathematical definition by Luigi Guido Grandi in 1728, who gave its name in honour of the Genovese Countess Clelia Grillo Borromeo, who was a brilliant woman, amateur mathematician and enthusiast of natural sciences. The spherical equation of the Clelia curve is:

$$
\left\{\begin{array}{l}
r=R \\
\lambda=c \theta
\end{array}(R=\text { sphere radius, } \lambda=\text { longitude, } \theta=\text { latitude, } c>0)\right.
$$

This kind of curve cannot be mistaken for a Spherical Helix, since it has not a constant slope, nor for a loxodrome or rhumb line, which would form a constant angle with the meridians.

In order to draw this curve accurately, a dedicated Autolisp function has been programed in AutoCAD to generate a Spline that matches with the Clelia curve proposed by Vandelvira (Fig. 7). From a practical and a mathematical point of view, the spatial distribution of the voussoirs is quite more harmonic than De L'Orme's proposal. Nevertheless, this design is not absolutely perfect, since the voussoirs are not disposed in a brickwork layout. This fact could cause a structural weakness and ease the movement of the masonry under load. However, this issue can be easily solved by dividing the equator into an odd number of parts and taking two divisions per voussoir so, in this way, the pieces would follow the brickwork layout. Another practical problem that arises in Vandelvira's proposal is the lack of a keystone. The upper pieces become more and more smaller and the carving process may be difficult. This problem would be solved by putting the last pieces together in order to get a single voussoir. 

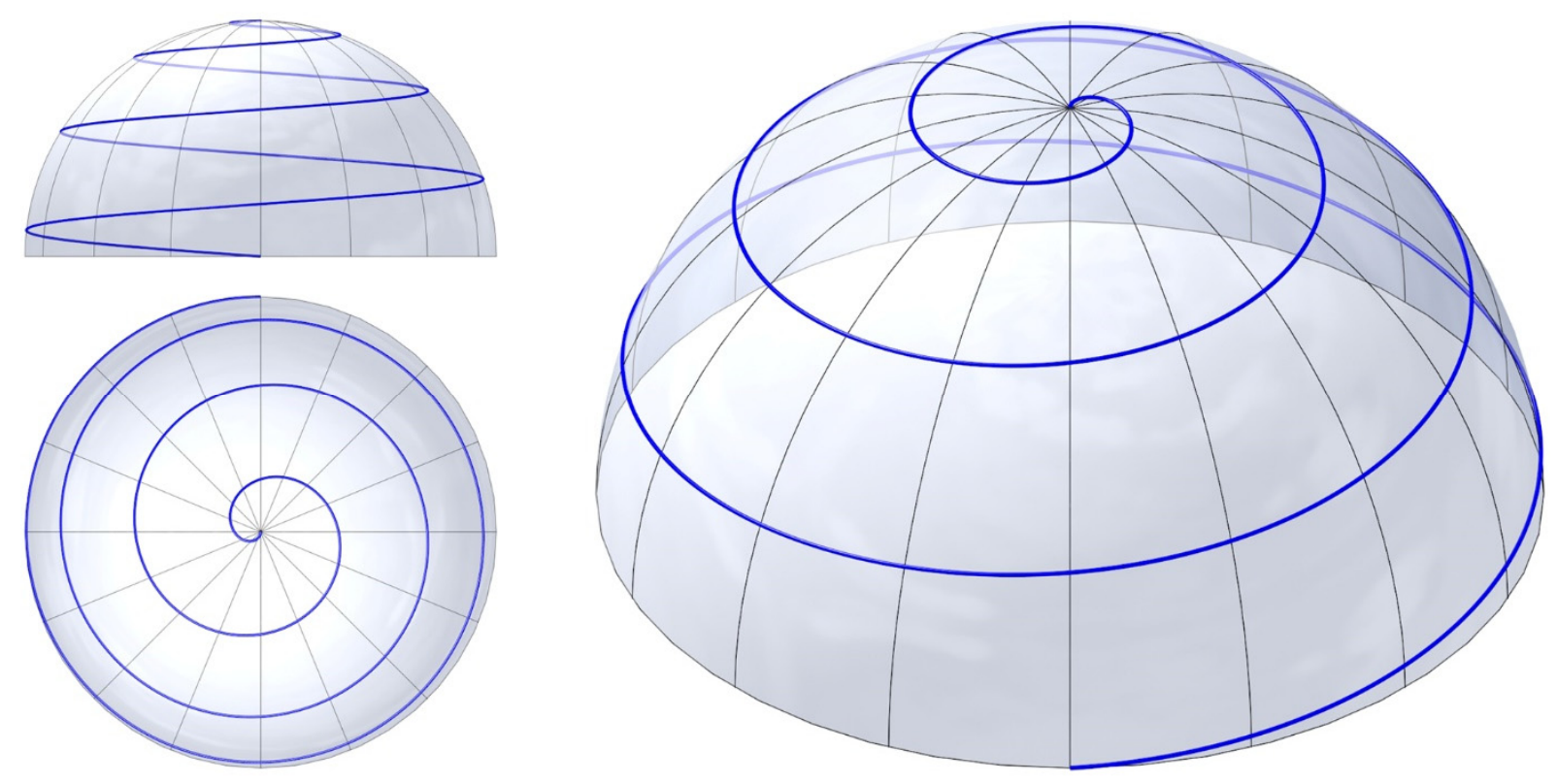

Fig. 7 Intrados face of Vandelvira's dome. The spatial curve is a Clelia or Spherical Spiral

Unlike in De L'Orme's proposal, Vandelvira defined a method to obtain the intrados templates based on determining the irregular quadrilateral inscribed in the intrados faces of the voussoirs. He only needed the true size of their diagonals and three of their edges. The geometrical procedure can be deduced by carefully reading the textual description, that can be sometimes a bit confusing.

Vandelvira explains how to obtain the true size of the diagonals correctly, in the same way that it would by achieved by using modern technical drawing. That is, the true size of a line segment can be obtained by measuring the hypotenuse of a rectangular triangle, in which one of their sides measures the same as the horizontal projection of the line segment, while the other side is equivalent to the height difference between the line segment endpoints.

However, he does not apply this correct procedure when obtaining the real distance between the lower points of the template, since, as the author indicates, are measured directly from the plan. Actually, these points are almost on a horizontal line, so this consideration would produce minor inaccuracies.

Vandelvira finished the intrados templates, by adding circumference arcs to approximate the portion of the Clelia curve defining the beds edges of the voussoir. These arcs were obtained by tracing the circumference arcs whose radius is the generatrix of a cone tangent to the spherical surface of the dome at the lower point of the Clelia portion. This fact justifies the straight line at the lower part of the templates in the voussoirs of the lower part of the dome presented by Vandelvira, since the tangents to the sphere in that points are so vertical that produces an arc of a huge radius.

Vandelvira considers this irregular quadrilateral as being flat, when actually it is not. Certainly, it is difficult to provide a perfect solution to this problem using flat templates because, as mentioned before, it involves developing a non-developable surface.

Vandelvira did not specify how the template had to be traced, but the more accurate way to carry out the transfer process would be to use a semi-rigid template placed on the spherical surface pre-carved in the voussoir. If the template were totally rigid, only three of their points would touch the spherical surface. The optimal position would be achieved when laying the template over the endpoints of its 
major diagonal, while the endpoints of the other diagonal were equally separated from the spherical surface. Then, thanks to the flexibility of the template, this points would be forced until touching the spherical surface. In practice, despite of causing some geometrical deviations, the stonecutter would surely try to lay the entire template on the spherical surface. That would be achieved with more or less difficulty depending on the concavity and may cause wrinkles on the template. Nevertheless, it would be admissible for the habitual cases.

To estimate the accuracy of the template, a three-dimensional CAD model of its deformation and its transference was obtained and compared with the spatial spherical quadrilateral of the intrados face. There was found minor differences, since the maximum deviation between homologous points was under $2 \%$ of the radius of the dome. This maximum was measured at one of the endpoints of the minor diagonal of the template. The method by Vandelvira to approximate the portion of the Clelia curve resulted very accurate as the measured deviations on the curves were above the maximum mentioned values. Logically, the maximum deviation was measured on the template corresponding to the first voussoir, as is the biggest one. Consequently, this deviation values would be perfectly admissible in practice, since the mortar joint would absorb this little differences. That proves that Vandelvira provided a very good solution for such a complex vault.

The proposals that will be analysed onwards, are derived from De L'Orme Teatrise. As mentioned by Rabasa (2003), the first case appeared in the unpublished manuscript by Jean Chereau entitled Le Livre de L'Architecture (ca.1600). The only copy of this manuscript is kept in the Municipal Library of Gdansk (Poland) [ms. 2280]. This case is almost an exact copy of De L'Orme's proposal, as it is shown in Fig. 8. Like De L'Orme, Chereau said nothing about the construction of the templates.
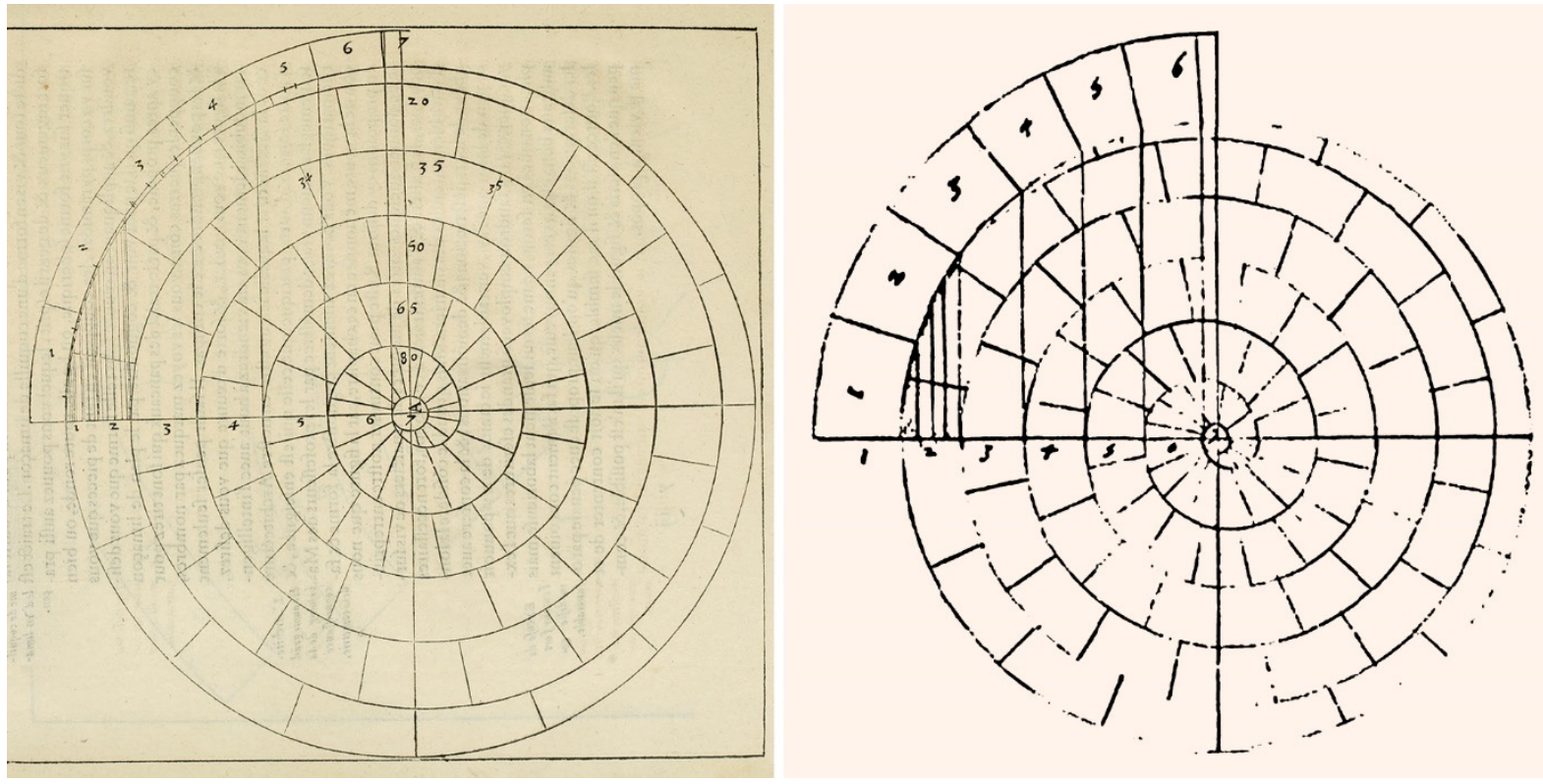

Fig. 8 Comparison between the proposal by De L'Orme (1567:120) (left) and the case in the unpublished manuscript by Jean Chereau (right). Picture of Chereau's manuscript obtained from Rabasa (2003:1682)

Milliet Dechales (1674) exposed in his Treatise Cursus seu mundus mathematicus a similar version of De L'Orme's proposal, which is more didactic but worse in the quality of the engraving.

The author entitled this case "Spiraliter testudinem efformare" (Spiral-shaped Shell) and the illustration was accompanied with a textual explanation that says nothing about the construction of the volute, which is quite more complex that De L'Orme's one. It may seem, at first sight, that is a unique fourcentres volute, but the better fitting hypothesis was achieved with a combination of three tangent 
volutes. The first volute has four centres that are located in a square that is inscribed in the keystone circle and rotated $45^{\circ}$. The second one has also four centres, but they are located on another square, which is inscribed in the previous one and passes through the medium points of their edges. Finally, the third volute has two centres, which are located on the vertical diameter (Fig. 9).
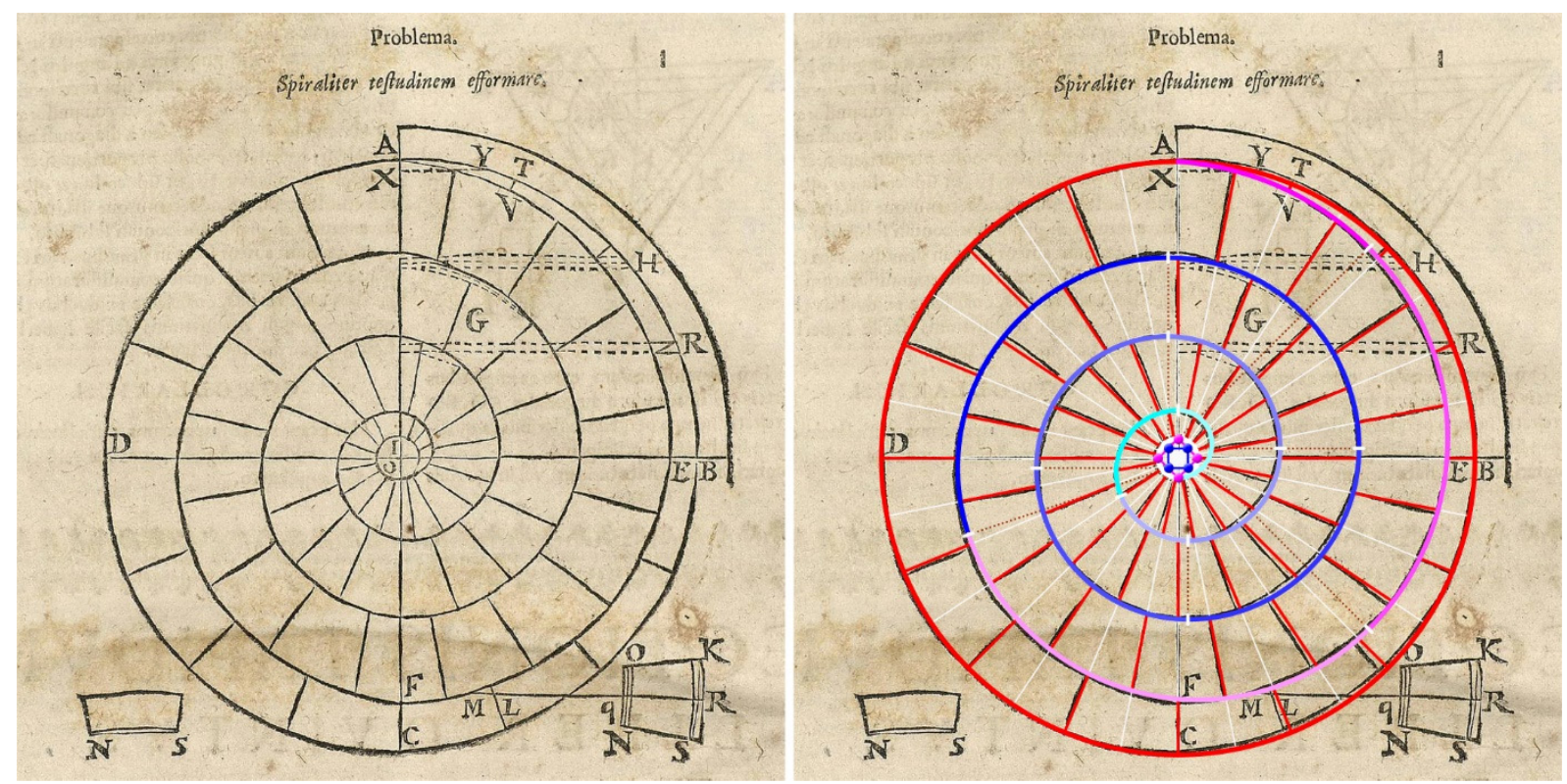

Fig. 9 Illustration in the treatise by Dechales (1674:681). Proportions and Geometrical modelization

The complete volute makes three and a half turns to reach the keystone. The spatial curve was obtained by projecting this volute on a hemispherical sphere surface. As it can be seen in Fig. 10, this case produces a voussoir distribution that is even more unbalanced than De L'Orme's one, due to the minor number of turns. As the volute designed by Dechales is not tangent to the equator of the sphere, there is an abrupt curvature change at the beginning of the spatial curve.
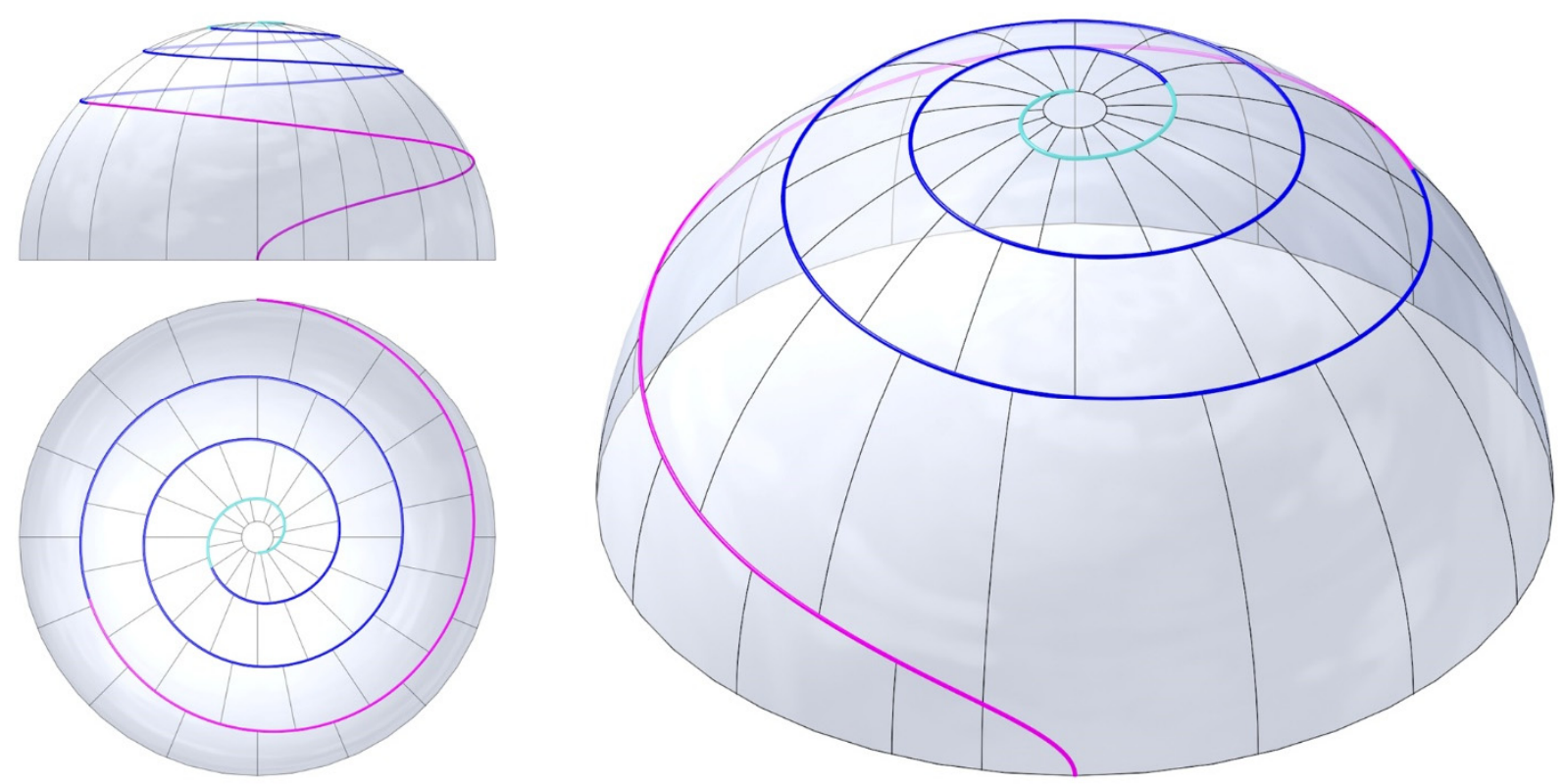

Fig. 10 Intrados face of Milliet Dechales' dome. The spatial curve generated by projecting the volute on the hemisphere 
Milliet Dechales, at last, explained a method to trace the intrados templates. This method can even be understood by observing the illustration so it is quite descriptive. Nevertheless, the intrados template is badly represented and very disproportionate, since the drawing does not follow properly the instructions exposed in the text. The author embraced the idea of using an auxiliary template from De L'Orme's proposal and he managed to provide a reasonable method. Firstly, he traced what would be similar to the intrados templates of two auxiliary conventional spherical voussoirs. One of them would be inscribed in the considered voussoir, while the other would circumscribe it. This auxiliary traces define the position of the four corners of the final template. and on its symmetry axis can be placed two additional points to trace the curves of the beds, that are simplified as circumference arcs. Dechales made a mistake in his method, as he indicated that the radius of the contour arcs has to be taken from the plan, measuring from the considered point to the centre of the dome. This would produce a different radius if compared to the habitual method for developing the cone surface. This difference would be quite important in the templates of the lower voussoirs, while, in the corresponding to the upper ones, it would be minimal as the generatrixes of the cone become more horizontal as ascending.

In order to estimate the accuracy of this method, the same previous procedure was carried out. As it was foreseen, the accuracy increased as ascending. The comparison in the taller voussoir at the lower part of the dome, resulted in a maximum deviation between homologous points of about $7 \%$ of the radius of the dome, which was measured approximately in the mediums points of the curve defining the edge of the lower bed. The comparison corresponding to voussoirs of the second turn showed a better fit between the edges of the beds, with maximum deviations about $3 \%$, while the fitting in the last turns was almost perfect. This method could have been improved considerably if considering the appropriate radius for the arcs of the templates.

An almost identical proposal was presented by the Spanish presbyter, architect and mathematician Tomás Vicente Tosca in his treatise entitled Compendio Mathematico, published in 1707. It is evident that this proposal is based on Milliet Dechales, but he made some changes when tracing the volute and, unconscientiously, transformed completely the solution. He designed a quite simple two centres volute, in which one of this centres was placed in the centre of the dome, causing accidentally an interesting solution that is a mixture of a conventional spherical multi-row dome and a single-row spherical dome (Fig. 11).
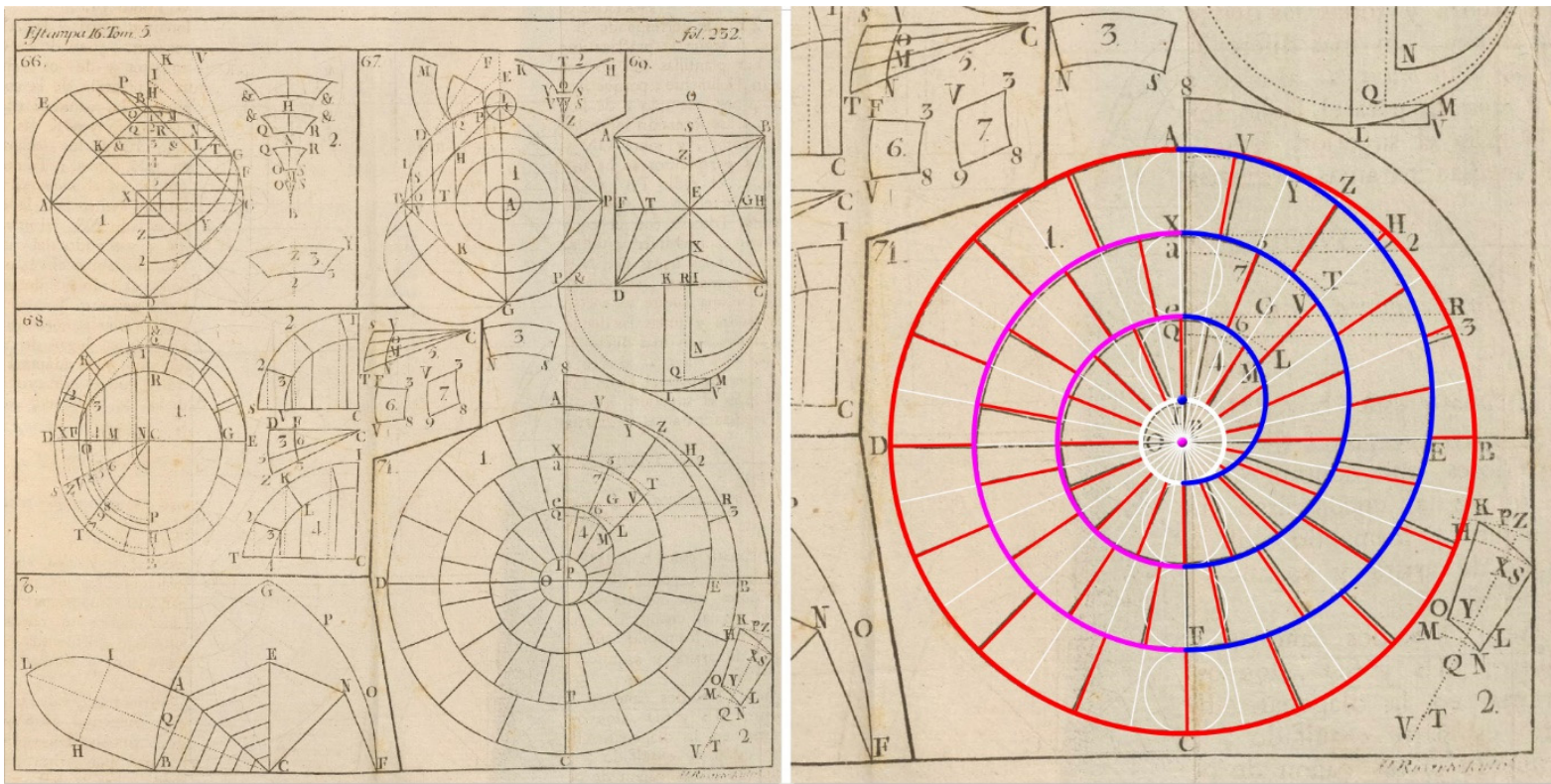

Fig. 11 Illustration in the treatise by Tosca (1707:232). Proportions and Geometrical modelization 
It is clear that the author was not aware of this fact, because in the text description he mentioned that each voussoir of the dome would require a specific template: "Esta bóveda tanto como tiene de ingeniosa, tiene de trabajosa, porque cada una de sus piedras necesita de diferentes plantillas" (Tosca 1707:230).
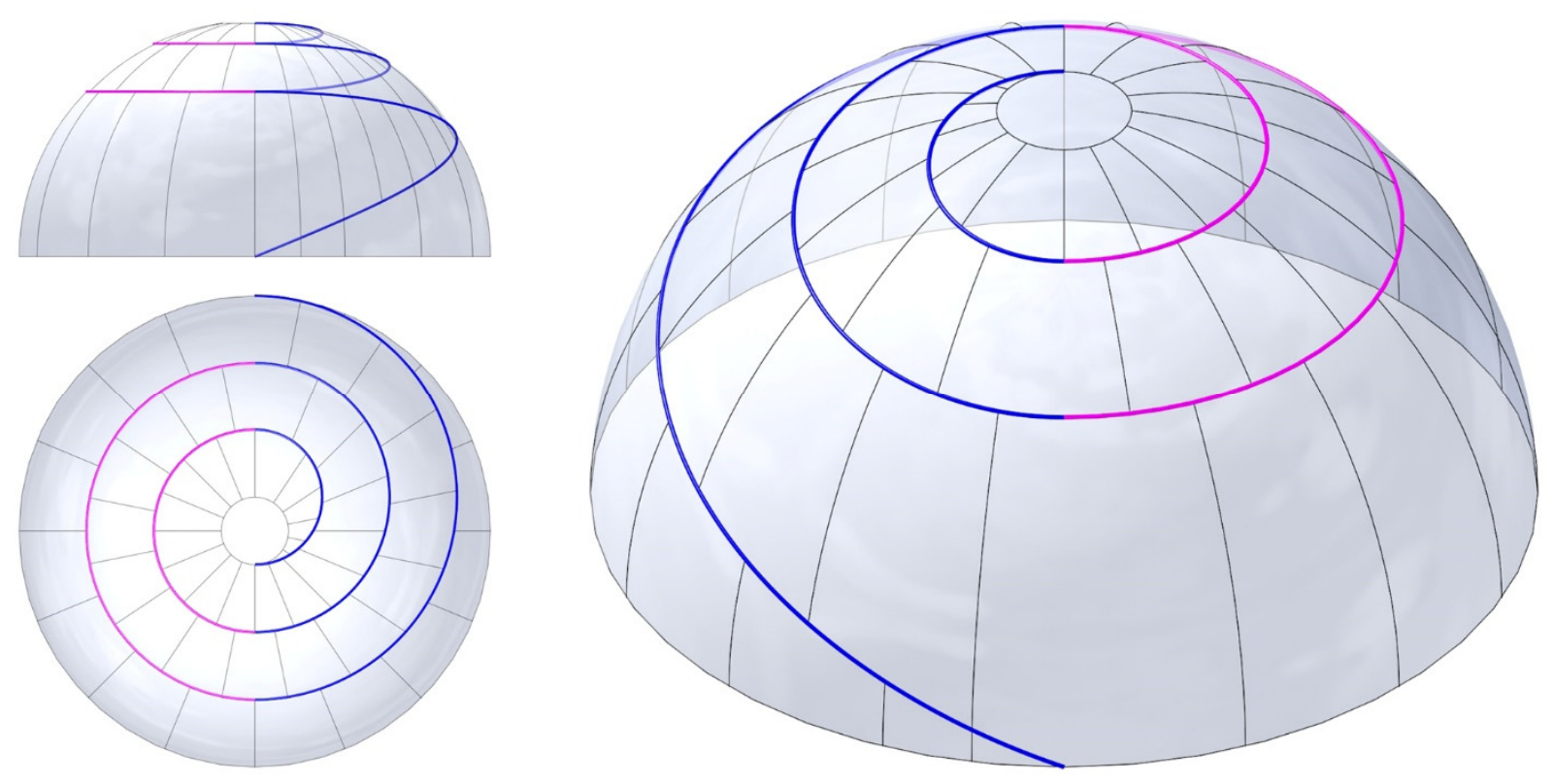

Fig. 12 Intrados face of Tosca's dome. The spatial curve is horizontal in the half part of the dome

Actually, only the voussoirs located at the right part of the dome and those that are between both parts would require the methodology exposed by the author, while the rest would follow the conventional methodology and only one template per row would be necessary.

Unfortunately, the proposal, as it was conceived, is quite unbalanced (Fig. 12). It is a pity, as this solution could have been gorgeous if the left part of the volute had been traced as usual in the case of a multi-row spherical dome. That is, being the concentric circumference arcs of this part of the dome not equally separated in the plan projection. Their separation would derive, in this case, from the division of a meridian into equal parts and would result in a much more balanced voussoirs layout.

The method exposed by Tosca to trace the templates is almost the same as the one by Dechales. The only difference is that he makes a little simplification and specifies that the arcs defining the edges of the beds should pass through a point located on the construction axis and equally separated from their respective auxiliary arcs. Given that the differences are negligible; it is not necessary to carry out any further accuracy estimation.

To conclude this study case, it is worth it to mention that Juan de Portor y Castro included in his Architecture notebook (1708) the same proposal defined by Tosca. As it can be seen in Fig. 13, they are identical. This notebook is kept in the National Library of Spain [ms. 9114] 

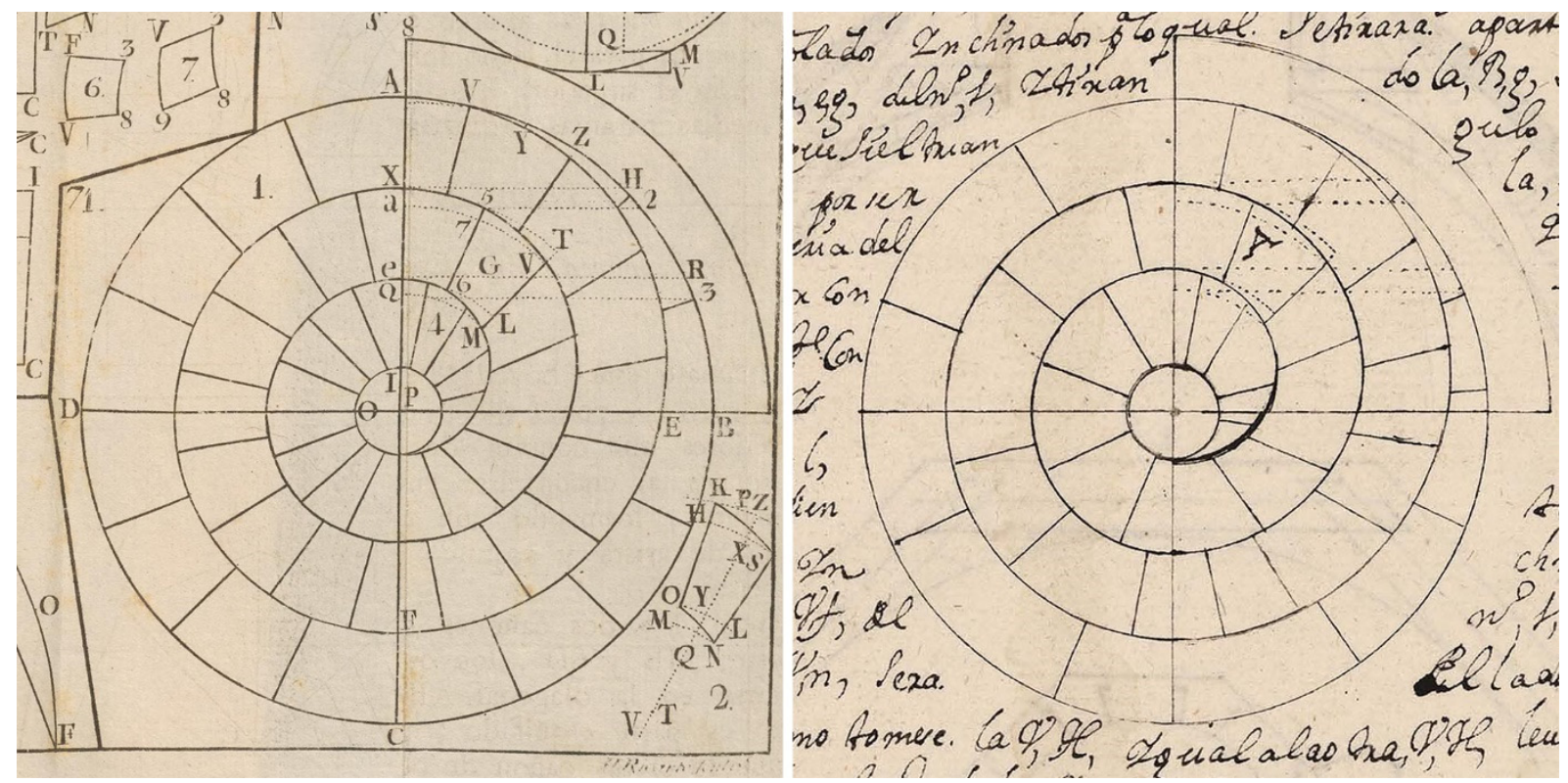

Fig. 13 Comparison between the proposal by Tosca (1707:232) (left) and the case in the manuscript by Juan de Portor $y$ Castro (1708:192) (right)

\section{Conclusions}

In order to summarize the features of every studied case, a comparison between all the spatial directrices of the domes it is shown in Fig. 14. The Clelia curve designed by Vandelvira (blue) produces the most balanced and elegant spatial distribution of voussoirs. As mentioned before, the problem is that the voussoirs does not follow a brickwork pattern, but this can be easily solved by dividing the equator in an odd number of parts and taking two divisions per voussoir. This consideration would also improve the rest of the cases, as they had to insert an extra-large voussoir every turn to follow the brickwork pattern. The solution by De L'Orme and their derivations result more unbalanced, as they were not spatially conceived. The projection of the volute on the hemisphere produced the worst distributions in the case by Dechales and in the mixed solution created accidentally by Tosca, which could be radically improved by properly distributing the concentric arcs of the volute.
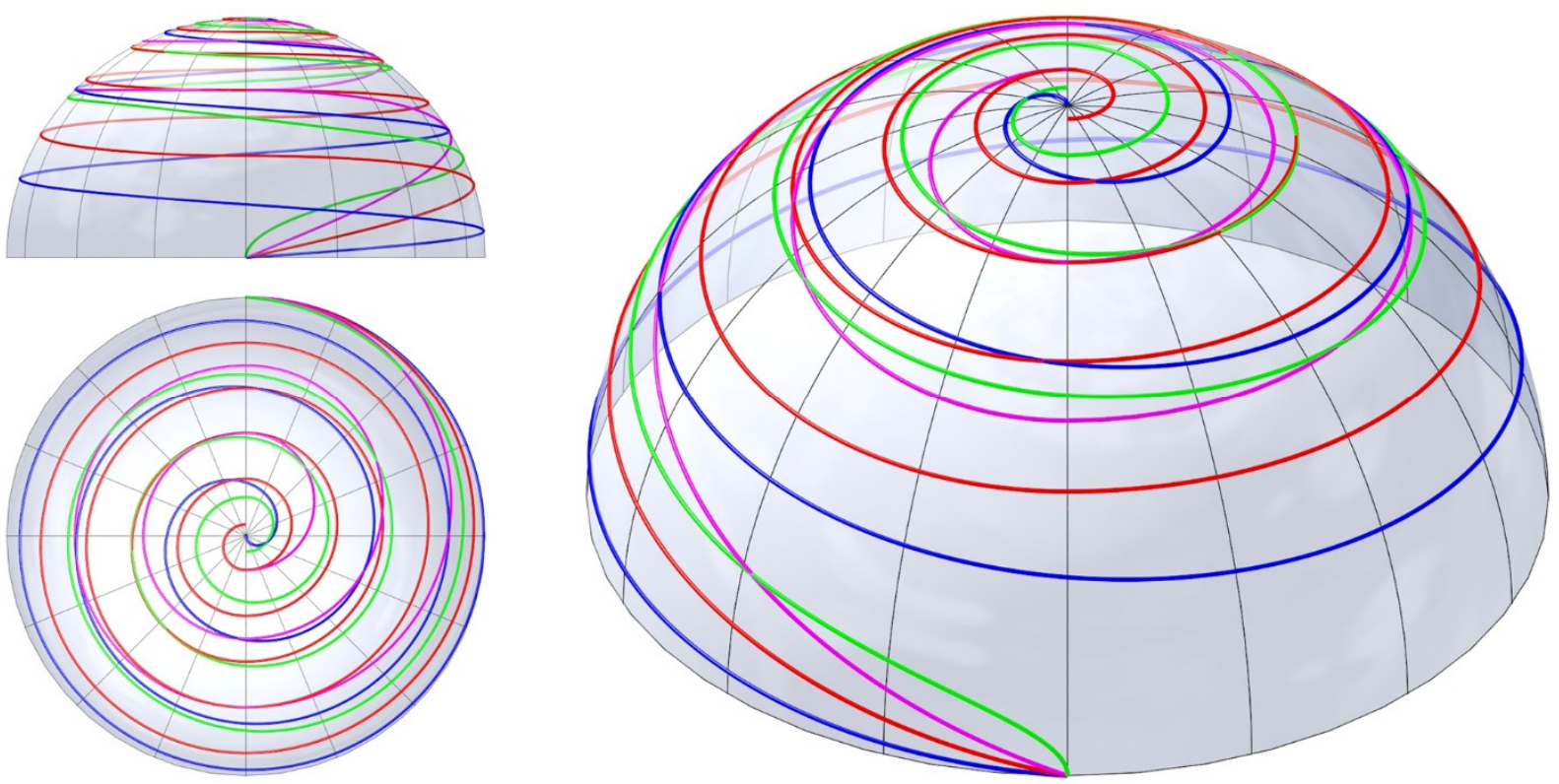

De L'Orme

Vandelvira

Dechales

Tosca

Fig. 14 Comparison between all the obtained spatial curves 
From a constructive point of view, the method provided by Vandelvira was the most accurate for tracing the templates. The method described by Dechales and adopted by Tosca had some conceptual mistakes that make it be less accurate in the lower part of the dome, where the curves defining de edges of the bed faces would not match properly with the spatial curve.

Due to the complexity of this domes, there are only six known constructed examples, all of them were carried out during the $16^{\text {th }}$ century in Spain. See Rabasa (2003) and Calvo et al. (2005). The oldest case is in the Cathedral of Murcia (early $16^{\text {th }}$ century). There are two examples attributed to the Spanish architect Rodrigo Gil de Hontañón in the Palacio de los Guzmanes (León) and in the Cathedral of Plasencia. There are two more cases located in the province of Cadiz; in the Churches of Medina Sidonia and San Juan de los Caballeros in Jerez de la Frontera. The last example is located in the Convento de Santa Catalina in Talavera de la Reina. Nowadays, with the development of digital 3D modelling tools and the Computer-Aided Manufacturing (CAD/CAM), it is possible to generate and construct easily such a complex model and with total accuracy. As an example, Fig. 15 shows a textured 3D model corresponding to the proposal by Vandelvira.

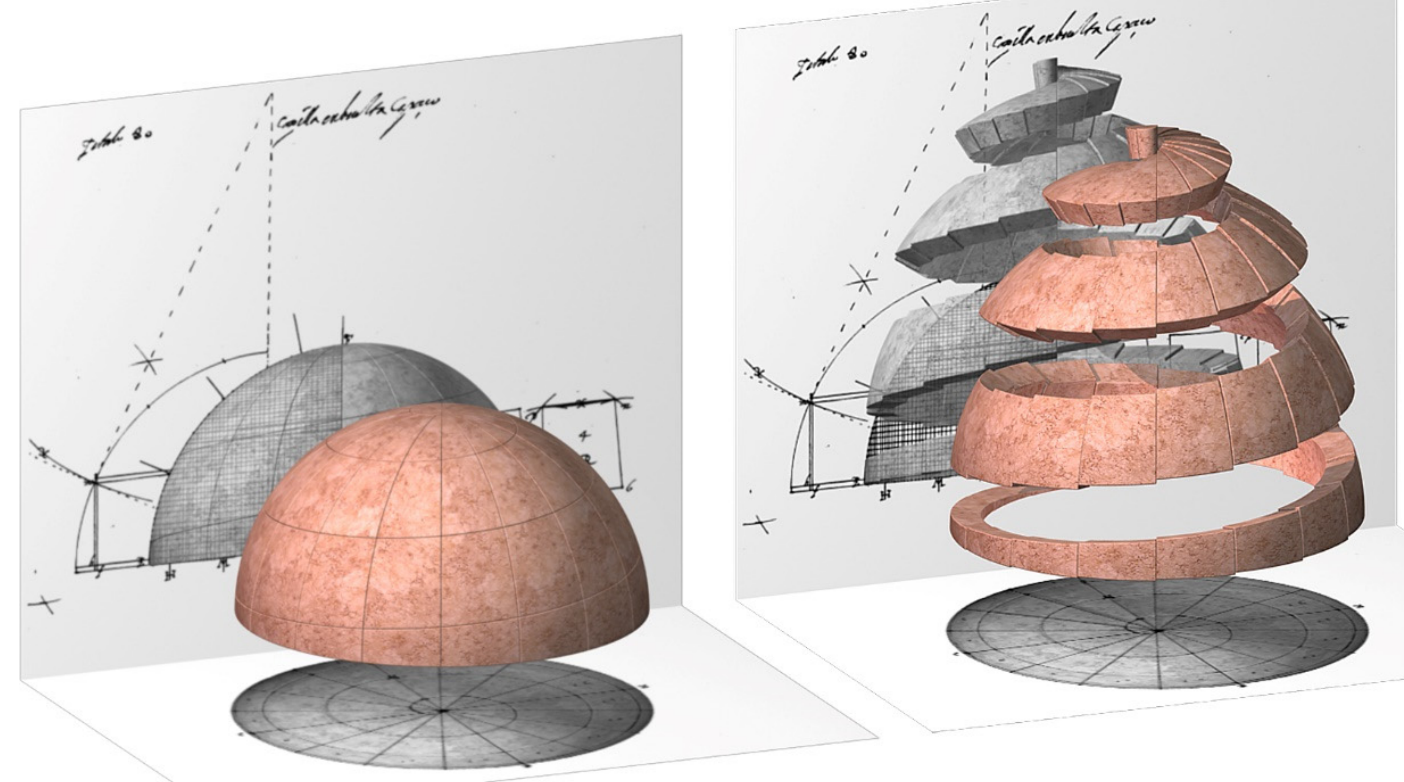

Fig. 15 3D textured model corresponding to the proposal by Vandelvira
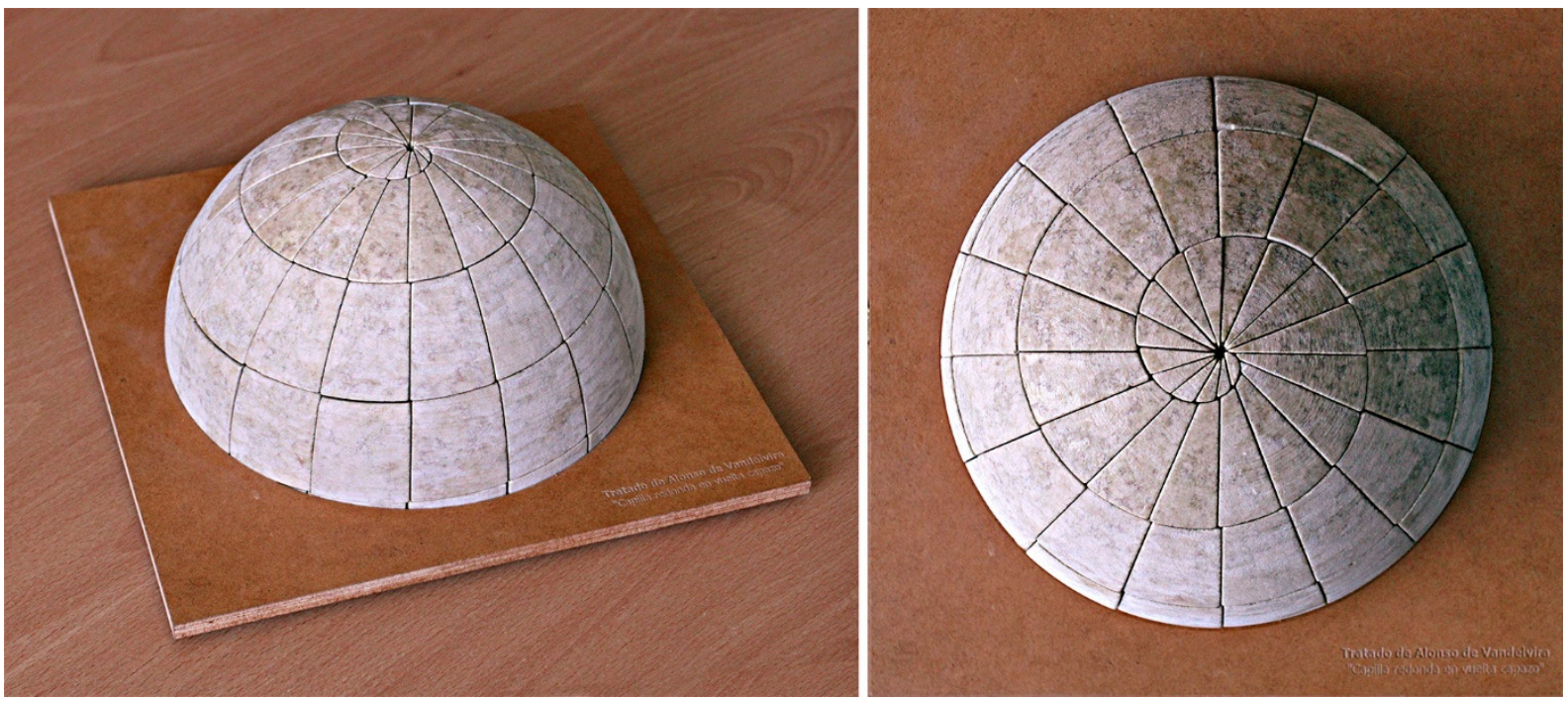

Fig. $163 D$ printed scale model obtained from the previous modelization using an injection 3D printer. 
The virtual model became real by means an injection 3D printer, which allows colouring the surfaces of the dome (Fig. 16). Every single voussoir of this scale model is independent and all the pieces are sustained only by gravity, without any kind of glue.

All these new tools ease the reading and comprehension of the ancient stereotomy treatises, whose concise drawings are sometimes difficult to understand, even for skilled geometers. The graphical methodologies that have been employed in this article will also be useful for future studies in the field of stereotomy and to promote the knowledge and dissemination of this complex and valuable geometrical heritage.

\section{References}

Barbé-Coquelin de Lisle, G. 1977. El tratado de arquitectura de Alonso de Vandelvira. Albacete: Caja de Ahorros Provincial de Albacete.

Calvo López, J., \& Alonso Rodríguez, M. A. 2005. Bóvedas renacentistas de intradós esférico y tórico en el antiguo Obispado de Cartagena. In XVI Jornadas de Patrimonio Histórico: intervenciones en el patrimonio arquitectónico, arqueológico y etnográfico de la región de Murcia, 67-84. Servicio de Patrimonio Histórico.

Calvo López, J., Alonso Rodríguez, M. A., Rabasa Díaz, E., \& López Mozo, A. 2005. Cantería renacentista en la catedral de Murcia. Murcia: Colegio Oficial de Arquitectos de Murcia.

De L’Orme, P. 1567. Le premier tome de l'Architecture. Paris: Féderic Morel

Fallacara, G., Barberio, M. 2018. An Unfinished Manifesto for Stereotomy 2.0. Nexus Netw J, 20, 519-543.

Gadaleta, R. 2018. New Stereotomic Bond for the Dome in Stone Architecture. Nexus Netw J, 20, 707-722.

García Baño, R. 2017. El manuscrito de cantería mss. 12686 de la Biblioteca Nacional de España. (Unpublished Doctoral Dissertation). Universidad Politécnica de Cartagena, Cartagena.

Gómez Martínez, J. 1998. El gótico español de la edad moderna. Bóvedas de crucería. Valladolid: Universidad de Valladolid.

Milliet Dechales, C. F. 1674. Cursus seu mundus mathematicus. Lyon: Officina Anissoniana

Palacios Gonzalo, J. C. 1990. Trazas y cortes de cantería en el Renacimiento español. Madrid: Ministerio de Cultura.

Palacios Gonzalo, J. C. 2015. Libro de trazas de cortes de piedras: copia manuscrita presentada por Bartolomé de Sombigo y Salcedo. Madrid: Instituto Juan de Herrera.

Rabasa Díaz, E. 2003. The single coursed ashlar vault. In Proceedings of the First International Congress on Construction History, 1679-1689. Madrid: Instituto Juan de Herrera.

Rabasa Díaz, E. 2013. Estereotomía: teoría y práctica, justificación y alarde. Informes de la Construcción, 65 (Extra-2), 5-20.

Tosca, T. V. 1707. Compendio Mathematico. Valencia: Antonio Bordazar. 